\title{
The Current State of Sustainable Development in Ghanaian Technical Universities
}

\author{
John Frank Eshun ${ }^{1 *}$ and Maame Afua Nkrumah ${ }^{2}$
}

${ }^{1}$ Department of Interior Design Engineering, Takoradi Technical University, Ghana

${ }^{2}$ Centre for Languages and Liberal Studies, Takoradi Technical University, Ghana

\begin{abstract}
Our sustainable future is currently not clear as we continue to unsustainably use our natural resources for modern civilization, urbanization and technological advancement. The need for change in attitude towards the environment and a diligent search for using the environment sustainably are therefore, on the lips of everyone. Universities however, are especially placed in the diligent search for sustaining the environment given their combined mission of research, civic education and engagement. The purpose of this article therefore, was to find out the extent to which Ghanaian Technical University (GTUs) are fulfilling this role.

The study design was descriptive. Data was gathered from four GTUs using semi-structured questionnaires. The quantitative component, measured on a three-point Likert scale was analyzed using descriptive statistics (percentages) with the help of the Statistical Package for the Social Sciences (SPSS). The qualitative component was analyzed using thematic analysis. One of the key findings of the study was that, although energy and water sustainability were generally part of the competencies required of student, sustainable projects, pollution management, recycling and the use of sustainable building materials were rarely considered. A key recommendation was that energy and water conservation and development issues should be made part of the range of courses offered by technical universities.
\end{abstract}

Keywords: Sustainable development; Education; Policy and energy management

\section{Introduction}

Our natural resources - air, water, soil, wildlife and ecosystems are our most precious commodities nevertheless, they are constantly being destroyed. This is a source of worry to many given that we depend on them for life. Granted, the environment's response to human actions can be gradual and smooth however, resulting drastic consequences may be difficult, expensive and sometimes impossible to reverse [1,2]. Also, any damage to the environment may have local, regional and global implications. For example, excessive usage of wood as fuel is already creating considerable environmental problems (e.g. deforestation and destruction of ecosystems) especially, in the Sahel. It is therefore not surprising that Sustainable Development (SD) is currently high on the agenda of most African countries and the world at large [3-5].

Sustainable development as defined by Brundtland [6] is the systematic, long-term use of natural resources in such a way that they are available for future generations. Bugaje [3] similarly defines SD as a pattern of development that delivers basic environmental, social and economic services without threatening the viability of natural, built and social systems upon which these services depend. The goal of SD has been to create and maintain prosperous social, economic and ecological systems whilst preserving it for future generations [7].

Universities worldwide have accordingly embraced the SD movement since the 1980s. Their key role has been to understand the factors that affect local, regional and international quality of life and produce new knowledge that enhances the adaptation capacity of the environment towards it. Also, they are to instill in students the responsibility of reflecting on how their behaviour and decisions affect the environment globally now and, in the future, [8]. Currently, more than 1000 academic institutions, worldwide have signed international declarations towards implementing sustainability - some in motion well before the United Nations Conference on Environment and Development. Various landmarks reached by universities in the process include:

1. The Magna Charta of European Universities (1988);
2. The Talloires Declaration of University Presidents for a Sustainable Future (1990);

3. Halifax document 'Creating a Common Future: An Action Plan for Universities' (1991);

4. The Copernicus 'Universities Charter on Sustainable Development' (1994);

5. The Lu" neburg Declaration on Higher Education for Sustainable Development (2001);

6. The Ubuntu Declaration on Education and Science and Technology for Sustainable Development (2002);

7. The Graz Declaration on Committing Universities to Sustainable Development (2005); (2008);

8. The G8 University Summit Sapporo Sustainability Declaration

\section{The G8 University Summit: Statement of Action $(2010)[7,9]$.}

The signing of such international declarations however, is not enough given that it takes more than written policies, strategies, declarations and action plans to achieve sustainability. Awareness creation covering the following issues among other for example, is important: the life-cycle of the impacts of human activities on earth systems, control of greenhouse gases, land and energy uses, consumption patterns, pollution and transport, campus greening, use of renewable energies to ensure continuous supply, erosion and

*Corresponding author: John Frank Eshun, Vice Chancellor, Department of Interior Design Engineering, Takoradi Technical University, P.O. Box 256, Takoradi, Ghana, Tel: +233244111719; E-mail: rector@tpoly.edu.gh

Received October 03, 2017; Accepted April 05, 2018; Published April 10 , 2018

Citation: Eshun JF, Nkrumah MA (2018) The Current State of Sustainable Development in Ghanaian Technical Universities. J Civil Environ Eng 8: 307. doi: 10.4172/2165-784X.1000307

Copyright: @ 2018 Eshun JF, et al. This is an open-access article distributed under the terms of the Creative Commons Attribution License, which permits unrestricted use, distribution, and reproduction in any medium, provided the original author and source are credited. 
desertification, management of organic substances, recycling, waste management, garbage and sewage treatment, and the life cycle analysis of products etc. All these are directly connected.

Folke et al. [2] present two approaches to the ongoing change of social-ecological systems. The first approach attempts to control change using rigid control mechanisms. The second uses planned management actions and subsequent monitoring of data to test hypotheses and build an understanding of ecosystem dynamics. The latter essentially requires working with all key stakeholders. For example, the value of flexible community-based systems of resource management tailored to specific situations and supported by all - governmental agencies, appropriate Nongovernmental Organizations (NGOs), staff, students etc. are priceless in ensuring that locals become more actively involved in environmental issues. Contextualization is important in ensuring that people have a personal commitment in preserving the environment for future generations. Of course, implementing SD approaches fully in a University is not an easy task. Nonetheless, some universities (e.g. University of British Columbia, Canada, University of Sonora, Mexico), have been successful in doing this, demonstrating that it can be done [10].

Interestingly, a review of international evidence shows that very few studies in this sector have been conducted by Ghanaians and African at large. Also, the focus of most studies examining sustainability issues has been on indicators instead of: (a) actual gaps in terms of what institutions are supposed to do and what they are actually doing in the area of sustainability and (2) the way forward. As argued by Filho, [7] ensuring sustainability in a university should cover the following concrete areas: (a) governance and policies (b) environmental green travels (c) engagement with industry (d) energy management (e) curriculum (f) research and (g) projects.

This article, therefore, reviewed the current state of SD within Ghanaian Technical universities and the way forward so as to ensure systematic integration of SD in the universities. The study specifically addressed the following two research questions:

a. What is the current state of SD in Ghanaian Technical universities in the areas of - curriculum, governance and policies, green travels, engagement with industry and energy management?

\section{b. What is the way forward?}

An understanding of these matters would help identify SD gaps that need attention and improvement. Perhaps, by making the university community aware of any identified gap; commitment, long-term action and change in behavior patterns at the institutional level may be fostered. The long term expected outcomes are the development of skills and attitudes necessary for working as responsible citizens who think and behave in ways that sustain the environment, knowing that our actions today affect future generations both locally and globally.

\section{Methodology}

The design of the study was descriptive. Four Ghanaian Technical Universities - Accra Technical University (ATU), Kumasi Technical University (KTU), Takoradi Technical University (TTU) and Cape Coast Technical University (CCTU) were involved in the study. The first three universities are the oldest technical institutions in Ghana which started as trade schools, through to Polytechnics and recently technical universities. Thus, it is expected that, they may be more developed. The last University is one of the new universities that came about as a result of the government's policy of a Polytechnic in each of the ten regions in Ghana. However, it is important to note that the findings of this study may not be applicable to other universities significantly different from those used for the study. Hence, contextualization of the study findings is emphasized.

The participants for the study included management members (e.g. Academic Deans, Estate and Development Officers and Heads of Departments, HoDs), and staff (e.g. lecturers and administrators). The management members were selected purposely because of the key role they play in policy formulation and implementation. These were contacted by appointment through telephone calls. The staff selected from each institution however, were selected using simple random sampling techniques. That is, one lecturer and administrator were selected from each office visited. If more than one lecturer or administrator was present, participants were selected based on their gender in relation to the number of males and females selected from that institution.

The actual data collection process started after official permission to conduct the study was obtained from each institution in both written and oral forms. The semi-structured questionnaire developed for both management and staff was accordingly administrated. The questionnaire was divided into two parts. The first part solicited background information while the second part focused on the following: curriculum development, governance and policies, environmental green travels, engagement with industry and energy management. These areas were carefully selected to reflect the various areas of SD examined by previous researchers as recommended by Filho [7].

The 42-item questionnaire contained both close-ended and openended questions. The structured items were on a three-point Likert-type scale ranging from agree (1) to disagree (3) and a four-point Likerttype scale ranging from very often (1) to never (4). The Likert scale was appropriate because every point on the scale provided a continuum for respondents to express their views leading to more explanation as the points on the scale were explained and discussed. However, the use of the Likert scale presented certain challenges. For example, it is possible that the range of responses provided limited the responses of the respondents. The addition of the open-ended questions however, lowered the prejudgment of issues and allowed experts and non-experts to air their views.

The problem of measurement in research is often addressed by the concepts of validity and reliability. These two basic issues apply to both quantitative and qualitative research approaches. In terms of validity, the instruments were piloted using respondents and procedures similar to the one used in the main study. The feedback received helped in identifying ambiguities, difficult questions and items that did not have adequate range of responses. Accordingly, all unnecessary, difficult and ambiguous questions were discarded, re-worded or re-scaled. The piloting also gave advance warning about where the main study could fail. In simple terms, piloting the instrument helped improve the internal validity of the questionnaire. Also, a table of specification was used in selecting the questionnaire items so as to ensure that all relevant issues were covered. The mixed methods approach adopted further improved the quality of the study. Reliability was achieved by the use of quotes to ensure that respondents' views were rightly presented.

The study was designed to achieve a $100 \%$ response rate (100 out of the 100 questionnaires sent out). Nevertheless, only 85 questionnaires constituting $85 \%$ were received within the time allowed. For the structured items, frequencies and percentages were generated using SPSS whereas the open-ended questions were coded and categorized according to emerging themes.

\section{Findings}

As presented in Table 1, a total of 85 participants from Accra (24), 
Cape Coast (19), Kumasi (21) and Takoradi (21) Technical Universities provided data for the study. That is, $28 \%$ (24 respondents) from Accra, $22 \%$ (19 respondents) from Cape Coast, and 25\% (21 respondents) each from Kumasi and Takoradi Technical Universities. In total, the study involved 48 (57\%) males and 37 (43\%) females. The majority (48\%) had master's degree while very few $(4 \%)$ had doctorate degree. The rest had first degree and below. Their average working experience was 2.7 (standard deviation=1.4) which was in the range 5-8 years (Table 1).

\section{Current State of Sustainable Development in GTTUs}

The results of this study are presented under seven sub-themes in line with the objective and research questions of the study. These are: curriculum development, governance and policies, environmentalgreen travels, engagement with industry, benchmarking, energy management and the way forward. Details are presented below:

\section{Curriculum development}

The results of the study in the area of curriculum development are presented on Table 2. According to the table, many (75\%) of the respondents agreed that energy and water management were generally, part of the competencies required of students in GTUs. The majority (58\%) also agreed that some of their courses dealt with SD issues. Others (64\%), similarly, indicated that SD issues were embedded in their programmes. As to whether some courses have been changed to reflect current SD trends or not, the response of the majority (48\%) was positive, although a minority (34\%) was not sure. The overall picture is that to some extent, some effort has been put into ensuring that SD is made part of the curriculum.

\section{Governance and policies}

The participants were generally divided over the issue of governance and policy in the area of SD. For instance, whereas $34 \%$ of the participants agreed that they had an environmental policy in their institution, the same percentage was not sure of its availability. The

\begin{tabular}{|c|c|c|c|}
\hline University & Male & Female & Total \\
\hline Accra & 12 & 9 & 21 \\
\hline Cape coast & 12 & 7 & 19 \\
\hline Kumasi & 13 & 8 & 21 \\
\hline Takoradi & 11 & 3 & 24 \\
\hline Total & 48 & 37 & 85 \\
\hline
\end{tabular}

Table 1: Demography of respondents. same was true of the extent to which energy management issues were emphasized. Whereas $36 \%$ had the view that this was done, another $34 \%$ were not sure of this. The respondents were similarly divided over: (i) the appraisal of SD projects, (ii) dissemination of SD information, (iii) the choice of environmentally responsible suppliers and (iv) the application of SD criteria in selecting contractors, subcontractors, suppliers, etc. The views of the participants on the three main strands of responses employed by the study (agreed, not sure and disagree) were very similar - ranging from $30-36 \%$. These mixed responses suggest two things. First, the probability that the issues raised were not happening and second, perhaps these happenings were not communicated. The majority additionally mentioned that campus notice boards, prospectus and websites were hardly used to give prominence to SD issues. In any case, the overall picture is that, the area of governance and policy was probably problematic. However, an area like transportation was strongly managed as indicated by the majority (41\%) (Table 3 ).

\section{Environmental green travels}

One strategy employed by many universities trying to sustain their environment is environmental green travel. This strategy emphasizes a reduction in the extent to which harmful emissions especially, those from petroleum products are released into the atmosphere. Table 4 presents the views of the respondents on how this strategy was employed by the selected GTUs. According to the table, most people (44\%) travelled using their own cars. Very few people always shared cars $(13 \%)$, used buses $(11 \%)$, worked from home (8\%), left their cars at home once a week (7\%), actually walked $(6 \%)$ or travelled by bicycles (3\%). This finding is rather unfortunate given that car share, leaving one's car home once a week etc. for instance, can reduce the extent of atmospheric pollution. These notwithstanding, the majority indicated that they sometimes biked or walked (55\%) for health reasons and travelled by passenger cars (37\%).

\section{Engagement with industry}

The study further looked at the extent to which GTUs are engaging with industry. The evidence as indicated by the majority (42\%) was that GTUs rarely worked closely with environmental agencies for $\mathrm{SD}$, although some form of cooperation has always existed. For example, in the area of project execution, a minority (31\%) indicated that the universities always shared close links with environmental agencies. Nevertheless, in terms of working with environmentally friendly industries and sharing best practices with them, the majority

\begin{tabular}{|c|c|c|c|}
\hline Item & Agree \% & Not sure \% & Disagree \% \\
\hline Issues of energy and water use management are part of the competencies required in our Technical, Vocational and Education Training (TVET). & 75.3 & 16.9 & 7.8 \\
\hline Some of our courses deal with sustainable development. & 58.4 & 31.2 & 10.4 \\
\hline Some of our courses/programmes have been changed to reflect current SD trends. & 63.5 & 27 & 9.5 \\
\hline Issues of energy and water use management are embedded in our programmes. & 44.7 & 34.2 & 21.1 \\
\hline
\end{tabular}

Table 2: Curriculum development.

\begin{tabular}{|c|c|c|c|}
\hline Item & Agreed \% & Not sure \% & Disagree \% \\
\hline We have an environmental policy. & 33.8 & 33.8 & 32.4 \\
\hline Energy management is strongly emphasized. & 35.5 & 34.2 & 30.3 \\
\hline We appraise sustainable development projects. & 35.5 & 30.3 & 34.2 \\
\hline Campus notice boards, prospectus and websites are used to give prominence to sustainable development issues. & 29.5 & 29.5 & 41 \\
\hline Sustainable criteria are applied in the selection of contractors, subcontractors, suppliers etc. & 30.1 & 34.2 & 35.7 \\
\hline Goods are bought from environmentally/socially responsible suppliers. & 33.3 & 31.9 & 34.8 \\
\hline Strong resource management including transportation is practiced. & 40.8 & 32.9 & 26.3 \\
\hline
\end{tabular}

Table 3: Governance and policies. 
Citation: Eshun JF, Nkrumah MA (2018) The Current State of Sustainable Development in Ghanaian Technical Universities. J Civil Environ Eng 8: 307. doi: 10.4172/2165-784X.1000307

Page 4 of 6

\begin{tabular}{|c|c|c|c|}
\hline Item & Always $\%$ & Sometimes \% \\
\hline Car drive & 44.2 & 29.9 \\
\hline Car share & 13.3 & 42.7 \\
\hline Passenger car & 34.6 & 37.2 & 25.9 \\
\hline Motor cycle & 0 & 29.4 \\
\hline Bus & 10.5 & 52.6 & 9.2 \\
\hline Bicycle & 2.6 & 39.7 & 34.2 \\
\hline On foot & 6.4 & 36.9 \\
\hline Work from home & 8.2 & 39.7 \\
\hline Leave car home a day in a week & 6.8 & 53.9 \\
\hline Rike a day & 1.4 & 5.7 \\
\hline
\end{tabular}

Table 4: Environmental green travels.

\begin{tabular}{|c|c|c|}
\hline \multicolumn{1}{|c|}{ Item } & Always \% & Sometimes \% \\
\hline We work with environmentally friendly industry & 28.9 & 44.7 \\
\hline Sharing of good practice with friendly industries & 25.3 & 45.3 \\
\hline We have close links with environmental agencies for sustainability & 31.6 & 26.4 \\
\hline We have associated with these agencies during the execution of projects & 31.2 & 26.3 \\
\hline We network with local communities to promote sustainable development & 15.4 & 27.3 \\
\hline Source: Field survey, 2016 & 41.5 \\
\hline
\end{tabular}

Table 5: Engagement with industry.

\begin{tabular}{|c|c|c|c|}
\hline Item & Always \% & Sometimes \% & Rarely \% \\
\hline We network with local communities to promote sustainable development & 15.4 & 39.7 & 44.9 \\
\hline We link up with governmental and local authorities responsible for the sustainable community agenda & 17.5 & 40 & 42.5 \\
\hline We benchmark with other institutions & 18.2 & 40.3 & 43.5 \\
\hline We undertake volunteering activities to promote sustainable development & 10.3 & 46.2 & 28.2 \\
\hline
\end{tabular}

Table 6: Benchmarking.

\begin{tabular}{|c|c|c|c|}
\hline Item & Always \% & Sometimes \% & Rarely \% \\
\hline Sustainable energy project & 15 & 38.8 & 46.2 \\
\hline Minimization of waste & 16.2 & 55 & 28.8 \\
\hline Micro generation of energy & 14.7 & 26.7 & 58.6 \\
\hline Waste management & 30 & 40 & 30 \\
\hline Recycling of paper, bottles, cans, food, plastics, batteries & 7.8 & 16.9 & 75.3 \\
\hline Pollution management/control & 14.1 & 35.9 & 50 \\
\hline Biomass and solar panels & 14.3 & 24.7 & 61 \\
\hline Use of sustainable building materials, e.g. straw bales, timber, earth and clay & 9.2 & 31.6 & 59.2 \\
\hline Solar energy - energy efficiency & 14.3 & 23.4 & 62.3 \\
\hline Alternative energy systems/technologies, e.g. double glazing & 10.1 & 21.7 & 68.2 \\
\hline Availability of awareness, creating champions on sustainable development through discussions, advice, etc. & 12.2 & 40.5 & 47.3 \\
\hline Source: Field survey, 2016 & & & \\
\hline
\end{tabular}

Table 7: Energy environment.

constituting $45 \%$ in each case mentioned that these were only done sometimes (Table 5).

\section{Benchmarking}

Related to the universities' engagement with industries is the extent of benchmarking which may usually occur between the universities and their local communities and authorities, as well other institutions. Although the universities sometimes undertook volunteering activities to promote sustainable development in their immediate environment as indicated by the majority (46\%), the overall picture concerning benchmarking was not too good. This is because the majority respectively indicated that the universities rarely benchmarked with local communities (45\%), local authorities (42\%) and other institutions (44\%). In the view of others, however, benchmarking with these stakeholders sometimes, rather than rarely occurred (Table 6).

\section{Energy environment}

The energy environment in GTUs was looked at from two main perspectives: sustainable energy projects and pollution management/ control. These perspectives were important to discuss because they have the potential of reducing the exploitation of natural resources if properly managed. Regarding the utilization of sustainable energy projects, the general picture as indicated by the majority $(46 \%)$ was that, these were rarely done, although a minority forming $39 \%$ mentioned that at least, these were sometimes done. Specific areas under sustainable energy projects examined by this study include: minimization of waste, microgeneration of energy, waste management and recycling. In the area of waste minimization, the majority forming $55 \%$ indicated that the universities sometimes minimized and managed waste. Other measures such as micro generation of energy and recycling of paper, bottles, cans, food, plastics, and batteries were however, seldom done. For example, 
many of the respondents (75\%) mentioned that GTUs hardly did any form of recycling. The majority constituting $59 \%$ similarly indicated that GTUs hardly generated energy internally (Table 7). These findings suggest that government needs to put some resources for research in these areas, perhaps.

The case of pollution management/control was not too different from the case of sustainable energy projects. Generally, this was seldom done as stated by the majority (50\%). Specific areas discussed under this perspective include: the use of sustainable energy sources, building materials, alternative energy systems/technologies and energy efficiency. Regarding sustainable energy sources such as biomass and solar panels, the study showed that these were rarely utilized as mentioned by the majority (61\%). The majority forming $59 \%$ similarly mentioned that sustainable building materials such as straw bales, timber, earth and clay were seldom used. The evidence regarding energy efficiency and use of alternative energy systems was the same. For instance, the universities as indicated by the majority $(62 \%)$ hardly ensured energy efficiency through the use of solar energy. Alternative energy systems/technologies such as double glazing was also, rarely employed. This view was shared by the majority (68\%). Awareness creation and the championing of SD issues through discussions, advice, etc. were also problematic as mentioned by the majority (47\%) (Table 7).

In summary, the results of the study were looked at from six distinct perspectives namely: curriculum, governance and policies, environmental-green travels, engagement with industry, benchmarking and energy management. Thematic summary of the findings is as follows:

In the area of curriculum, the study indicated that generally, energy and water use management issues were part of the competencies required of students. Also, to some extent, some courses had been changed to reflect current SD trends.

On governance and policy issues, participants were divided on whether the universities had an environmental policy or not. The majority held the view that such a document was available, but this view was a highly contested. The appraisal of SD projects, dissemination SD information, the choice of suppliers who were environmentally/socially responsible and the application of SD criteria in selecting contractors, subcontractors, suppliers etc. were similarly contested. The study further showed that campus notice boards, prospectus and websites were hardly used to give prominence to SD issues.

Evidence in the area of environmental green travels pointed to the fact that the majority of staff in the Technical University community travelled by personal cars, instead of sharing a car, using passenger cars or bus. On the other hand, key ways of sustaining the environment such as leaving one's car at home, biking, walking and working from home were not the usual practice for the majority, although others sometimes rode/walked for health reasons.

In the areas of engagement with industry and benchmarking, the overall finding was that the Technical Universities hardly shared a close link with environmental agencies although sometimes they shared some good practices. Similarly, the universities seldom benchmarked with local communities and authorities as well as other institutions. They however, sometimes undertake volunteering activities to promote sustainable development in their immediate environment.

The final area examined by the study was energy environment. The finding in this regard showed that sustainable energy projects and pollution management or control were rarely employed. The same was true of recycling, the use of sustainable energy sources such as biomass and solar panels and building materials such as straw bales, timber, earth and clay. Efficient energy management through the use of solar energy and alternative energy systems/technologies such as double glazing were also seldom utilized. The use of these mechanisms is important because they have the potential to reduce the exploitation of natural resources, and ensure the conservation of the natural environment.

\section{Discussion and Conclusion}

This section discusses key findings emerging from the study in relation to existing literature and contextual evidence. Overall, the following three key issues emerged from the study and are subsequently discussed: (1) the finding that information on SD is not readily available, (2) the need to include water and energy conservation and development issues in the curriculum of schools and universities and (3) the need for research into sustainable energy sources and mechanisms.

The first key issue borders on the availability of information on SD. The key task here is not only to 'spread the word' as it were, but to do so in a way that different audiences could be reached and sensitized. One interesting finding from the study was that campus notice boards, prospectus and websites were hardly used to give prominence to SD issues. This suggests that probably, information on SD was not readily available to the University community. Also, the fact that the participants were divided over whether the universities had SD policies or not implies that to some extent, there were problems with in this area. This finding was, however expected. As argued by Filho [11], it is paradoxical that although sustainability is one of the most important issues affecting modern society worldwide, awareness about it and a sense of worthiness of its value, is still confined to a small number. This is rather unfortunate given that a change in behaviour can be encouraged by informing and motivating people, for example, to apply ways of reducing environmental degradation [12]. In fact, it is only when people are well informed and entirely confident about what to do that they will be willing to move toward sustainability. So, the argument is that everyone should be adequately informed and involved in efforts geared toward SD.

The second issue is the inclusion of water and energy conservation and development issues in the curriculum of universities. It was quite significant to find that energy and water management were generally part of the competencies required of GTU students. Also, some courses had been changed to reflect current SD trends. Although this in itself may not be adequate, it is a good sign that at least something has been done for the long-term purpose of ensuring sustainability. Thus, in this way, students and staff from GTUs can be taught and motivated to play a key role in ensuring a better use of natural resources in the way they consume goods, purchase or even vote [11]. This initiative is important because, unless there were links between curriculum areas and the whole institution's approach to SD, SD would be largely ineffective [7]. Among other things, an improvement in the sustainability dimension of university programmes is necessary to enable the following SD goals to be achieved: (a) an enhancement of the quality of education provided to students, as well as the quality of research conducted and (b) the development of conservation ethics among students, staff and other groups.

The third issue discussed is the need for research into sustainable energy sources and mechanisms. One of the key findings of the study was that sustainable energy sources such as biomass and solar panels were seldom used by the technical university community. This is quite unfortunate considering: (a) the important role universities play in practicalizing issues of SD and (b) the fact that Africa is currently facing a serious energy crisis ironically not because of lack of energy resources, 
but because of the poor state of infrastructural support and appropriate technology to harness these resources, especially the renewable ones. According to Bugaje [3], excessive usage of fuel wood, for example, is already creating considerable environmental problems especially in the Sahel. The major alternative energy resources abundant throughout the African continent are solar energy (thermal and photovoltaic), wind energy, wood and biomass, and biogas production. However, as evidenced by the findings of this study, these are currently seldom explored. Thus, there is no doubt that the GTUs need to intensify research in this area, perhaps specifically looking at environmental conservation and sustainability in general in the short and long term.

Although some institutions have been successful in implementing SD initiatives, many have failed in putting these suggestions into practice because of a number of reasons, varying from lack of interest, to misconceptions and limited assigned resources. Key misconceptions in this area include the perception that sustainability is too abstract and broad to achieve. Similarly, resources for SD are often constrained by request for justification for requested funds given the keen competition for funds and resources within universities [13]. This notwithstanding, sustainability can be achieved in GTUs as most universities are trying to do.

\section{The Way Forward}

The recommendations made by this study need to be contextualized given that the study focused on only four GTUs instead of all six GTUs currently operating in Ghana. The recommendations were obtained from the open-ended section of the data collection instrument. The recommendations come through four main thematic areas - (1) what government should do; (2) governance and policies; (3) education and (4) change in attitude.

In the area of what the government should do, it was mentioned that a key responsibility of government is to set up a research-development fund or provide adequate resources for the universities and other mandated institutions to research into modern contextualized-practical ways of ensuring SD in Ghana. Interestingly, non-politicization of the issue was emphasized. This, according to the study participants, will to a large extent facilitate quality research into areas such as recycling, alternative energy sources, energy management etc. The energy sector in particular was rated as needing a lot of attention considering the recent challenges in the sector. Thus, the need to pay special attention to alternative energy sources such as solar: wind, biogas, biomass etc. which is more environmentally friendly was recommended.

In the area of governance and policies, the formation and implementation of SD policies in areas such as the purchasing, hiring, award of contracts and projects, reforestation and environmental pollution control or minimization etc. to ensure strict compliance with the SDGs were articulated. Also, campus designs should suit the use of bicycles so that it can be used as an alternative means of transport. The universities should also put in place monitoring and evaluation systems to ensure continuous SD. For instance, there should be a mechanism for monitoring effective and better use of energy in a way that ensures energy conservation e.g. the use of energy saving bulbs. The universities were further encouraged to engage efficiently with industries that have current, relevant environmental policies and practices to learn from them so as to develop policies that are practical and useful. Making energy and water conservation and development among other things part of the range of courses offered by the universities was further recommended for policy.
In the areas of education, regular workshops meant to educate and sensitize people on Sustainable Development Goals (SDGs) were mentioned. At the University level, environmental-green travel clubs and associations to promote and create awareness on the SDGs were articulated. This was one of the responses for the participants:

A: "Organize workshops and seminars to sensitize students, staff and the general public about sustainable development."

Change in attitude was also recommended. The need for attitudinal change and cooperation among all Ghanaians cannot be overemphasized. Areas needing change in attitude mentioned by the participants included: the use of environmentally friendly items/ materials in building, waste separation at home, indiscriminately waste disposal etc. It was further mentioned that motor/automobile drivers in particular, need to change their attitude towards cyclist and pedestrians in general so that they can feel safe and actually be safe on the road. This to some extent would encourage more people to consider travelling by walking or by bicycles. Change in attitude toward purchasing habits, recycling, and saving energy and/or water were additionally mentioned. Notice the responses of the following two respondents:

A: "Train students and staff to develop conservation ethics among other things"

B: "Motivate students to change the way they deal with waste, consume goods and even purchase"

\section{Acknowledgement}

My profound gratitude goes to the staff and management of the four Technical Universities for providing the necessary data for this study. Special thanks goes to the heads of the Universities and Mr. Enock Sey for proof reading this work.

\section{References}

1. Borne G (2010) A framework for sustainable global development and effective governance of risk. Lewiston, New York, Milen Press, USA.

2. Folke C, Carpenter S, Elmqvist T, Gunderson L, Holling CS, et al. (2002) Resilience and sustainable development: building adaptive capacity in a world of transformations AMBIO 31: 437-440.

3. Bugaje IM (2006) Renewable energy for sustainable development in Africa: A review. Renew Sust Energ Rev 10: 603-612.

4. Johnson DL, Ambrose SH, Bassett TJ, Bowen ML, Crummey DE, et al. (1997) Meanings of environmental terms. J Environ Qual 26: 581-589.

5. Chertow MR (2000) The IPAT equation and its variants. J Ind Ecol 4: 13-29.

6. Brundtland GH, Visser W (1987) Our common future: Report of the 1987 world commission on environment and development. The Top 50 Sustainability Books 52-55.

7. Filho WL (2011) Applied sustainable development: A way forward in promoting sustainable development in higher education institutions. World trends on education for sustainable development, Frankfurt: Peter Lang scientific publishers.

8. Barth M, Godemann J, Rieckmann M, Stoltenberg U (2007) Developing key competencies for sustainable development in higher education. Int $\mathrm{J}$ Sustainability Higher Edu 8: 416-430.

9. Waas T, Verbruggen A, Wright T (2010) University research for sustainable development: Definition and characteristics explored. J Clean Prod 18: 629636

10. Filho WL (2010) Sustainability at universities: Opportunities, challenges and trends. Frankfurt: Peter Lang scientific publishers, Germany.

11. Filho WL (2010) Teaching sustainable development at university level: Current trends and future needs. J Balt Sci Educ 9: 273-284.

12. Parkin S (2010) The positive deviant: Sustainability leadership in a perverse world. London: Routledge, UK.

13. Filho WL (2000) Dealing with misconceptions on the concept of sustainability IJSHE 1: 9-19. 